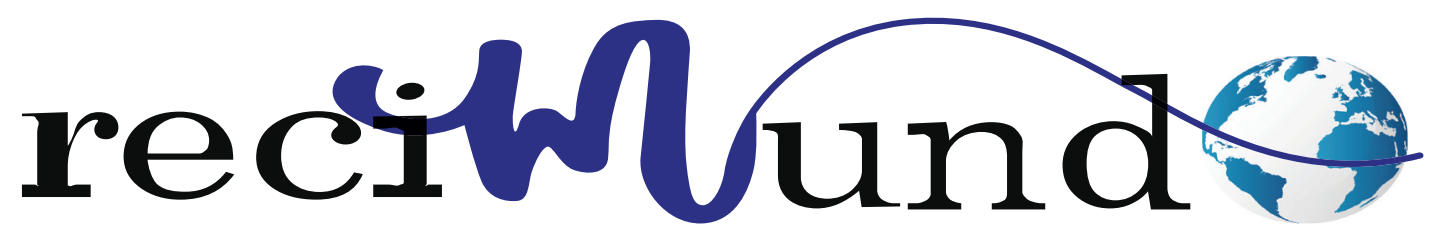

Revista Científica Mundo de la Investigación y el Conocimiento

DOI: 10.26820/recimundo/4.(2).mayo.2020.64-74

URL: http://recimundo.com/index.php/es/article/view/824

EDITORIAL: Saberes del Conocimiento

REVISTA: RECIMUNDO

ISSN: 2588-073X

TIPO DE INVESTIGACIÓN: Artículo de Revisión

CÓdigo UNESCO: 32 Ciencias Médicas; 3201 Ciencias Clínicas

PAGINAS: 64-74

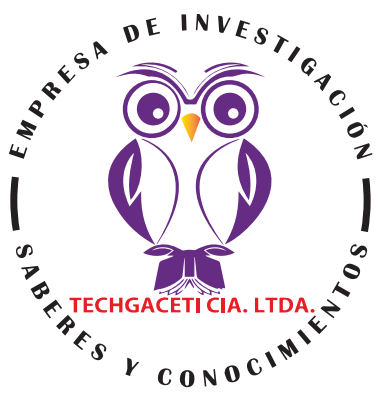

\title{
La PCR como prueba para confirmar casos vigentes de COVID-19
}

PCR as a test to confirm current cases of COVID-19

PCR como um teste para confirmar os casos atuais de COVID-19

Luz Angélica Salazar Carranza'; Fulton Estenio Maldonado Santacruz²; Janeth Aurora Cruz Villegas³

\section{RECIBIDO: 15/03/2020 ACEPTADO: 20/03/2020 PUBLICADO: 20/05/2020}

1. Magister en Bioquímica Clínica; Química Farmacéutica; Universidad Técnica de Babahoyo; Babahoyo, Ecuador; Isalazar@utb.edu.ec; (D) https://orcid.org/0000-0003-4172-6601

2. Magister en Gerencia de Servicios de Salud; Diploma Superior en Gestiona de Desarrollo de los Servicios de Salud; Doctor en Medicina y Cirugía; Universidad Técnica de Babahoyo; Babahoyo, Ecuador; fultonmsc@ gmail.com; (D) https://orcid.org/0000-0001-8640-808X

3. Magister en Planificación Evaluación y Acreditación de la Educación Superior; Diploma Superior en Gestión de Desarrollo de los Servicios de Salud; Licenciada en Laboratorio Clínico; Tecnóloga Medica en Laboratorio Clínico; Universidad Técnica de Babahoyo; Babahoyo, Ecuador; janeth-cruz71@hotmail.com; (DD https://orcid. org/0000-0003-1406-6249

CORRESPONDENCIA

Luz Angélica Salazar Carranza

Isalazar@utb.edu.ec

Babahoyo, Ecuador

๑ RECIMUNDO; Editorial Saberes del Conocimiento, 2020 


\section{RESUMEN}

Detectar la infección por SARS-CoV-2 mediante la PCR, implica utilizar una variante de esta técnica llamada RT-CPR, la reacción en cadena de la polimerasa con transcriptasa inversa. En tiempo real, muestra el nivel de fluorescencia pudiendo confirmar, en un 90\% de confiabilidad vírica, la infección vigente en el paciente. Diferentes estudios confirman que cuando esta prueba da positivo, ciertamente el paciente está infectado, pero no necesariamente si el resultado es negativo. La PCR presenta limitaciones que pueden ser compensadas con otras pruebas diagnósticas, pero sobre todo, con el criterio médico capaz de interpretar el cuadro clínico, y pueda tomar la decisión, de repetir la RT-PCR, si fuera necesario.

Palabras clave: PCR, RT-PCR, SARS-CoV-2, COVID-19, Prueba.

\section{ABSTRACT}

Detecting SARS-CoV-2 infection by PCR involves using a variant of this technique called RT-CPR, the reverse transcriptase polymerase chain reaction. In real time, it shows the level of fluorescence and can confirm, in $90 \%$ of viral reliability, the current infection in the patient. Different studies confirm that when this test is positive, the patient is certainly infected, but not necessarily if the result is negative. The PCR has limitations that can be compensated with other diagnostic tests, but above all, with the medical criteria capable of interpreting the clinical picture, and can make the decision, to repeat the RT-PCR, if necessary.

Keywords: PCR, RT-PCR, SARS-CoV-2, COVID-19, Test.

\section{RESUMO}

A detecção da infecção por SARS-CoV-2 por PCR envolve o uso de uma variante dessa técnica chamada RT-CPR, a reação em cadeia da polimerase com transcriptase reversa. Em tempo real, mostra o nível de fluorescência e pode confirmar, em 90\% da confiabilidade viral, a infecção atual no paciente. Diferentes estudos confirmam que, quando esse teste é positivo, o paciente certamente está infectado, mas não necessariamente se o resultado for negativo. A PCR possui limitações que podem ser compensadas com outros testes diagnósticos, mas, acima de tudo, com critérios médicos capazes de interpretar o quadro clínico, podendo tomar a decisão de repetir a RT-PCR, se necessário.

Palavras-chave: Teste de PCR, RT-PCR, SARS-CoV-2, COVID-19. 


\section{Introducción}

El Secretario General de la OMS Tedros Adhanom Ghebreyesus en la rueda de prensa celebrada el 16 de marzo del 2020, recomendaba "hacer pruebas, pruebas y más pruebas" (OMS, 2020), es la mejor estrategia de lucha contra la COVID-19. En esos momentos, las incógnitas sobre cuál de todas, y qué convenía medir, eran para resolverse de inmediato dada la urgencia que suponía la pandemia.

La Reacción en Cadena de la Polimerasa (PCR) fue la recomendación más obvia por ser la prueba del coronavirus más sensible. Su amplificación exponencial es capaz de reconocer incluso cantidades ínfimas del patógeno, porque bastan sólo cinco a diez copias de ARN del virus para que sea positiva. Esta técnica es muy conocida y ampliamente utilizada, y ofrece resultados en cuestión de horas.

La PCR, es una técnica genética de replicación de ADN que se ha utilizado desde que en 1983, Kary Mullis, un científico de Cetus Corporation, la concibiera como método para copiar ADN y sintetizar un ADN específico de un objetivo (diana) en grandes cantidades. Después de dos años del lanzamiento de la PCR, un equipo de Cetus se dio cuenta del alcance de éste importante invento del siglo XX, y vislumbró el impacto que podía tener en la biología molecular. Por ello, profundizaron sus investigaciones y perfeccionaron el proceso teórico en una realidad.

Hoy en día la PCR se utiliza para hacer test de paternidad, identificar cadáveres y detectar enfermedades. Y con el advenimiento de esta pandemia del COVID-19, ha servido para detectar el SARS-Cov2. Para esto último, es necesario aplicar una variante de ésta técnica: La reacción en cadena de la polimerasa con transcriptasa inversa (RT-PCR), ya que los coronavirus son virus de ARN monocatenario, y la PCR estándar se aplica sobre moléculas de ADN, no de ARN. La transcriptasa inversa sintetiza ADN a partir de una molécula de ARN, y de ésta manera, se puede aplicar la PCR cuantitativa para amplificar cadenas de ADN del SARS-Cov2, para su detección.

La RT-PCR confirma la enfermedad vigente en un $90 \%$ de confiabilidad, y no ofrece ninguna otra información para el estudio epidemiológico, como lo hacen los test de Inmunidad Adquirida, sobre quién se ha expuesto el virus y en qué forma (asintomático o no). Tampoco es muy rápida la técnica si considera la situación obviamente demandante de la pandemia, pero puede llegar a complementarse con otras técnicas rápidas de detección, en 15 min, que si bien no son más fiables, ayudan a la primera aproximación y en la atención ambulatoria.

La PCR como técnica molecular hasta el día de hoy, es la técnica molecular más recomendada, tal vez por la familiarización de su uso, o porque es la más viable en muchas latitudes del mundo.

\section{Metodología}

Se realizó una investigación documental y recolección de datos e información sobre los diferentes test para la detección del nuevo coronavirus SARS-CoV-2, siendo la PCR, la prueba de elección en casi todo el mundo, aplicando su variante con transcriptasa inversa. Abordando información científica de actualidad, se consideró la calidad y veracidad de la información recopilada, desglosando e indagando las nuevas terminologías referentes al COVID-19.

Una vez levantada la información recopilada, se procedió a elegir aquella basada en fuentes certeras, y respaldadas por criterios científicos. Toda la información giró en torno a la PCR como principal prueba diagnóstica para el COVID-19, e inevitablemente, también se estudió sobre otros grupos de pruebas, que no fueron expuestas en el presente artículo, salvo aquellas que pudieran ser de 
uso explicativo para el documento, como es el caso de las pruebas de detección rápidas y de las inmunológicas.

Para el enfoque documental descriptivo adoptado para la elaboración del presente documento, se recurrió a la consulta profesional de médicos para que corroboraran, descartaran, y agregaran información, según su experiencia en medio de la pandemia, para finalmente obtener la organización de los datos adecuados al tema.

El planteamiento del tema principal del artículo se fundamenta en las recomendaciones aportadas por la OMS, y la opinión de expertos alrededor del mundo que han tenido experiencia con la detección de los coronavirus.

\section{Origen de la PCR}

En 1983, cuando Kary Mullis trabajaba para Cetus, tuvo una idea revolucionaria. Se trataba de un proceso cíclico para amplificar exponencialmente pequeñas cantidades de ADN. Después de separarse a alta temperatura, dos cadenas de ADN podrían copiarse utilizando una molécula ADN polimerasa, cebada con oligonucleótidos cortos. En una serie de minuciosos experimentos realizados manualmente, Kary determinó las condiciones necesarias para que el proceso funcionara. Inicialmente, había usado un ADN-Polimerasa mesofílica aislada de Escherichia coli. Pronto se dio cuenta de que la ADN-Polimerasa Taq termoestable, originalmente aislada de Thermus aquaticus, un organismo descubierto en una fuente termal en el Parque Nacional de Yellowstone, era mucho más adecuada. Esta nueva en-zima permitió la simplificación y automatización de la PCR, sin necesidad de adicionar polimerasa en cada uno de los ciclos.

Cetus compró la Taq polimerasa de NEB (New England Biolabs), hasta que se emitió una patente que frenó su venta. Por eso, el equipo de Mullis dirigió su atención a otra polimerasa termoestable, conocida como ADN polimerasa Vent, que es producida por Thermococcus litoralis, un organismo que se encuentra en las fuentes hidrotermales de aguas profundas. Esta investigación condujo no sólo al perfeccionamiento de la técnica, sino también al descubrimiento inadvertido de la primera inteína estable al calor.

Muchas polimerasas fueron probadas y mejoradas, diferentes investigaciones lograron optimizar la PCR a lo largo del tiempo. El método se automatizó para que un segmento de ADN pudiera copiarse más de mil millones de veces en una o dos horas, y esto fue posible a el ciclador térmico creado por la compañía biotecnológica PerkinElmer de EE. UU, en 1987.

Como resultado, los análisis moleculares y genéticos que requerían grandes cantidades de ADN se volvieron considerablemente más fáciles. La técnica de la PCR, se convirtió en un éxito instantáneo y Cetus Corporation, vendió esta tecnología a varios compradores, y en el transcurrir de los años, cada corporación científica perfeccionó y adaptó la técnica según su aplicación:

- Se utiliza como "código de barras" para identificar las diferentes especies de animales.

- Se utiliza para determinar grados de parentesco e identificar individuos concretos, con la amplificación de secuencias repetitivas denominadas microsatélites.

- Ha permitido amplificar genes de ADN de momias, de especímenes preservados en colecciones de museo o de muestras forenses.

- Permite a la biología molecular, realizar mutagénesis dirigida mediante la introducción de cambios en los cebadores.

- Se utiliza como herramienta de diagnosis en epidemiología (bacterias, virus, parásitos) y también en la medicina (cáncer, enfermedades hereditarias). 
Está ultima aplicación es la que concierne al tema a tratar, porque la PCR, hace posible la realización de millones de copias de una sección de ADN en tan solo unas horas, obteniendo suficiente ADN necesario para su análisis. Este técnica innovadora y al mismo tiempo sencilla, permite a la medicina clínica diagnosticar y supervisar las enfermedades utilizando una cantidad mínima de muestra, como sangre o tejido.

Es evidente la importancia de comprender como funciona la PCR, aunque como médicos sólo interesen los resultados. Sólo conociendo el proceso, se realizará una toma de muestra correctas y las decisiones e interpretaciones correctas, para disminuir la probabilidad de obtener falsos negativos.

\section{La técnica PCR}

Antes de iniciar los ciclos de la PCR, se debe aislar el ADN de la muestra tomada, de una forma manual o automatizada. Esto dependerá del laboratorio y sus recursos. Por lo general, este es un proceso largo de múltiples pasos. Una vez aislado el ADN diana, se inician los ciclos de PCR.

En cada ciclo de la PCR se duplica al ADN diana, se trata de una reacción exponencial donde se generan más de mil millones de copias del ADN original en de 30 a 40 ciclos de PCR. Para ello, se realizan tres pasos en cada ciclo:

1. Desnaturalización: Se calienta a más de 90 grados Celsius (194 grados Fahrenheit), el tubo que contiene la muestra de ADN. Esto logra separar el ADN bicatenario en dos cadenas. La temperatura elevada rompe las uniones relativamente débiles entre los nucleótidos que componen el código del ADN.

2. Hibridación: Se aparean los cebadores $u$ oligos al DNA molde. La PCR no copia todo el ADN en la muestra, sino solo una secuencia muy específica de código genético, el objetivo al cual se dirigen los cebadores de la PCR. Así por ejemplo, la Chlamydia tiene un patrón de nucleótidos específico de la bacteria, entonces la PCR copiará solamente las secuencias de ADN específicas que están presentes en la Chlamydia y ausentes en las otras especies de bacterias. Para lograr esto, se utiliza trozos cortos de ADN sintético (cebadores, oligonucleótidos sintéticos) que se unen, o hibridan, solo a secuencias en cualquier lado de la región del ADN diana. Se utiliza un cebador por cada cadena de ADN. Estos dos cebadores se unen al comienzo de la secuencia que copiarán, delimitando la secuencia. En este paso el tubo se enfría y la fijación del cebador se produce entre 40 y 60 grados Celsius (104 y 140 grados Fahrenheit). Las dos cadenas están listas para ser copiadas (amplificadas).

3. Extensión: Copia de las cadenas delimitadas. Se eleva la temperatura aproximadamente 72 grados Celsius (161,5 grados Fahrenheit). "Cada uno de los extremos 3'-OH de los oligos apareados a lascadenas directa y reversa serán extendidos, generándose las cadenas hijas correspondientes. (Dorado Pérez, 2020)"

Una vez hecha dos copias del ADN por medio de la PCR, el ciclo comienza de nuevo, esta vez utilizando el nuevo ADN duplicado. Cada duplicado crea dos nuevas copias, y después de aproximadamente 30 o 40 ciclos de PCR, se crean más de mil millones de copias del segmento de ADN original de forma automática, en cuestión de horas.

Para el uso del diagnóstico clínico, la PCR es capaza de elabora suficientes copias del ADN diana a partir de la muestra clínica como para permitir el análisis, y la información suficiente para indicar tratamiento para la enfermedad diagnosticada.

Ante la pandemia por el coronavirus SARSCoV-2, y la enfermedad asociada COVID-19, 
cuya rápida propagación es de gran preocupación, y porque aún las investigaciones no han resultado concluyentes, ha sido de vital importancia contar con una prueba diagnóstica fiable para detectarlo.

La PCR como prueba para detectar la presencia de material genético específico del SARS-CoV-2, es la recomendada por expertos del todo el mundo. Dado que la PCR sólo amplifica cadenas de ADN, y los coronavirus son virus de ARN monocatenario positivo recubiertos por una estructura de glicoproteínas y lípidos. Por ello, se realiza una variante de la PCR estándar: la reacción en cadena de la polimerasa con transcriptasa inversa (PCR-RT).

\section{La RT-PCR para detectar el SARS-CoV-2}

Para detectar la infección por SARS-CoV-2 mediante PCR, se debe realizar la conversión del ARN monocatenario viral en ADN. Esto es la reacción en cadena de la polimerasa con transcriptasa inversa (RT-PCR), la prueba de oro que se está implementando contra COVID-19, y con buenas razones. Es in diagnóstico específico y sensible, lo que significa que las personas que dan positivo realmente tienen la enfermedad y ninguna de las personas portadoras del virus pasa la prueba como un falso negativo, a menos que la muestra tomada no contenga el virus (muestra nasal cuando la infección ya está avanzada, y ya está en los pulmones), o se halla alterado por alguna razón. Aun así, la RT-PCR cumple con dos criterios importantes: tasas de especificidad y sensibilidad de 90 \% o más.

El proceso comienza una vez que se recoge el material genético del virus a partir de un frotis de nariz o garganta del paciente a diagnosticar. Esta muestra pasa por un proceso de purificación porque a la más mínima contaminación de ADN puede alterar los resultados. Afortunadamente, hay productos disponibles para la detección y descontaminación.
La muestra de ARN obtenida purificada se mezcla con la Transcriptasa Inversa (y otros reactivos). Al momento de recolectar la muestra, también se está recogiendo material genético humano, bacteriano e incluso material genético de otros virus. Es decir, aquí habrá ADN de muchos orígenes al momento aplicar la Transcriptasa Inversa, pero no todo se amplificará en la PCR. Esta es una técnica dirigida a ciertas secuencias específicas, en este caso, secuencias del ADN retrotranscrito del virus SARS-CoV-2.

Tener el genoma completo del virus fue crucial para diseñar cebadores que detectarían sólo SARS-CoV-2 y no SARS-CoV o cualquier otro coronavirus estrechamente relacionado. Diferentes pruebas se dirigen a diferentes partes del genoma del SARSCoV-2, y la Organización Mundial de la Salud (OMS) ha emitido su propio protocolo que especifica los cebadores y procedimientos recomendados. Algunos países que pudieron desarrollar y desplegar sus propias pruebas de RT-PCR COVID-19, se basaron en el protocolo de la OMS, para evitar está problemática.

En la RT-PCR, la muestra del paciente se añaden al tubo de ensayo sondas que se unen únicamente a secuencias específicas del ADN retrotranscrito del virus y emiten fluorescencia.

Los marcadores se acoplan a las cadenas de ADN y emiten una fluorescencia, mientras la computadora del equipo mide y presenta en pantalla los resultados en tiempo real. También realiza un seguimiento de la magnitud de la fluorescencia después de cada ciclo. Al superar un determinado nivel, se confirma la presencia del virus.

El personal preparado supervisa también el número de ciclos que se tarda en alcanzar ese nivel para determinar así la gravedad de la infección. De allí se puede deducir que mientas menor sea el número de ciclos, más grave será la infección vírica. 
Por tanto, a mayor fluorescencia en la muestra, mayor cantidad de copias del ADN obtenidas mediante la retrotranscripción del virus SARS-CoV-2, permitiendo medir en tiempo real la cantidad de fragmentos de ADN que se van produciendo, logrando los dos posibles resultados:

\section{RT-PCR POSITIVA}

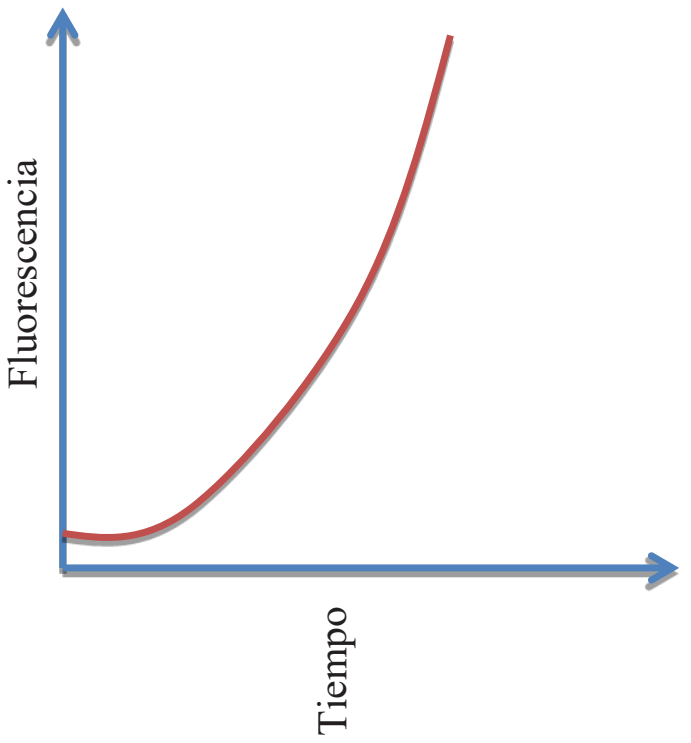

- Si se detecta un aumento de la fluorescencia durante la reacción de PCR, existe un claro indicio de la presencia de SARS-CoV-2 en el paciente.

- Si durante la prueba no se detecta un aumento de la fluorescencia durante la reacción de PCR, se podría afirmar que la prueba ha resultado negativa y, por tanto, el paciente no se encuentra infectado por el virus SARS-CoV-2.

\section{RT-PCR NEGATIVA}

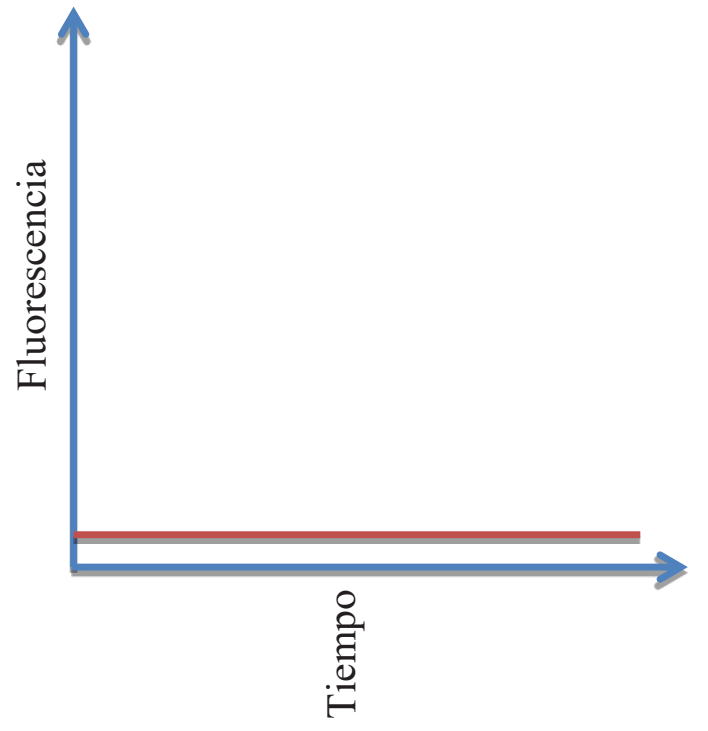

Figura 1. Reacción de PCR

Fuente: Elaboración propia, basado en SiNC, 2008. (ob. cit).

Tipo de muestras donde se puede aplicar RT-PCR

Existen varios estudios recientes en el que se toman diferentes muestras clínicas en pacientes con síntomas, para detectar material genético del coronavirus Covid-19 por RT-PCR, y para posterior análisis epidemiológico:

- Frotis oro-faríngeo

- Muestra nasal

- Sangre

- Orina

- Heces

- Leche materna
- Muestras de superficies inertes que se sospechen estén contaminadas con el virus.

Los resultados de algunos estudios mostraron que el material genético del virus Covid-19 se pudo detectar tanto en los frotis orofaríngeos como en las heces, pero no en orina ni en sangre. Por tanto, se podría pensar como hipótesis que el virus puede transmitirse también por las heces, además de saliva y aerosoles respiratorios. (Xie, y otros, 2019).

Otros estudios no consiguen ninguna evidencia de transmisión vertical, en madres 
positivas para COVID-19. Tanto el líquido amniótico y muestras de sangre de cordón umbilical de sus recién nacidos que fueron entregados por cesárea, resultaron negativas para el virus por SAR-Cov-2 aplicando RT-PCR. De igual manera, Las muestras de leche materna de las madres después de la primera lactancia también fueron negativas para este nuevo coronavirus aplicando RTPCR. (World Health Organization, 2020)

\section{Limitaciones de la RT-PCR como prueba diagnóstica para el SARS-CoV-2}

Existen varias limitaciones de la RT-PCR como prueba diagnóstica del SARS-Cov-2 en medio de la pandemia por COVID-19:

1. A pesar de que la RT-PCR detecta directamente el ARN del SARS-CoV-2 en las muestras tomadas de secreciones respiratorias del paciente, antes de que se formen los anticuerpos, logrando detectar el virus muy tempranamente, sólo lo hace cuando la infección está vigente. Es decir, que si la persona ha estado expuesta al virus anteriormente, enfermándose o transcurriendo la infección de forma asintomática, es imposible con esta prueba saberlo.

2. Los resultados correctos de la RT-PCR dependerán de la toma de la muestra correcta. El frotis o exudado, no siempre se realizan de forma correcta, peor aún si lo hace el propio pacientes en su casa. Por otro lado, el hisopo de algodón puede no recoger ninguna partícula vírica de la garganta, si la infección está avanzada, y el virus se concentra principalmente en los pulmones, porque la cantidad de virus alojada en la garganta varía enormemente en el curso de la infección.

3. Con ésta técnica es imposible saber si el material genético del virus está indemne, es decir, que la muestra contiene virus intactos, con capacidad de infectar. Esto significa que con esta prueba no sabremos si el SARS-CoV-2 encontrado en materiales inertes, pueden o no seguir contagiando. Hasta ahora, lo que nos puede afirmar la RT-PCR, es que el material genético SARS-CoV-2 está allí, jexiste! pero no sabremos, a ciencia cierta, si vivo o muerto.

4. Una gran limitación de la RT-PCR a la hora del diagnóstico de la infección, es que exige varias horas de trabajo en el laboratorio. Porque antes de aplicar la PCR, es decir, iniciar la amplificación, se necesita separar y purificar el ARN vírico del resto de la muestra del paciente, y luego realizar la transcriptasa inversa (sintetizar ADN a partir de una molécula de ARN). Además, del tiempo que requiere la prueba en si con sus ciclos sucesivos de calentamiento y enfriamiento. Esto no sería un problema, si no fuera una pandemia: Demasiadas pruebas, y mucho tiempo requerido para dar respuesta oportuna a todos esos pacientes.

En la actualidad, no se cuenta con una prueba diagnóstica del SARS-CoV-2 perfecta, e infalible, además que resultan ser costosas. Lo que cada institución de salud de cada país debe hacer es crear estrategias que tomen como herramientas todos los tipos de pruebas a su alcance, y la apliquen inteligentemente según los casos y los recursos con que se cuenten. Si la PCR es el método más accesible a la mayoría de los países, lo más idóneo es usarla tratando de solventar, en la medida de lo posible, sus limitaciones.

1. Para complementar la TR_PCR, es necesario contar con el apoyo de otras pruebas de diagnósticos que puedan servir para la vigilancia de la pandemia ya que como ya se explicó, la PCR sólo confirma la enfermedad vigente. No obstante, los análisis de sangre que detectan la inmunidad adquirida con las inmunoglobulinas $\mathrm{M}$ (IgM) y las inmunoglobulinas A $(\lg A)$, permiten conocer quién es ya inmune al virus y quien no lo es. La reacción inmunitaria tarda un tiempo en aparecer tras el inicio de los síntomas, 
de modo que los IgM IgA con resultado negativo, no descarta la infección, pero para eso está la PCR. La información que suministran las pruebas de inmunidad adquirida, es importantísima en los hospitales y en otras instituciones en que el contacto con personas infectadas es inevitable. El objetivo es realizar un análisis sistemático de la población permitiendo que las personas inmunizadas, se reintegren a la vida. La buena noticia es que ya existen pruebas rápidas (similares a una prueba del embarazo) que en pocos minutos muestran una reacción colorométrica, si la sangre contiene los anticuerpos en cuestión o no. Aunque no se ha verificado la fiabilidad de estas pruebas conforme a las normas legales, no quiere decir que no funcionen.

2. Para disminuir la cantidad de errores en la toma de muestras, se debe entrenar a muchos profesionales de la salud para que la realicen de forma eficaz, eficiente bajo las más estrictas normas de bioseguridad. Que sean capaces de discernir con criterio científico, según el cuadro clínico del paciente:

- Pacientes ambulatorios: Tracto Superior. Exudado nasofaríngeo/orofaríngeo. Se recoge en dos hisotopos para el análisis de virus con medio de cultivo, uno nasal y otro para garganta.

- Pacientes con enfermedad respiratoria grave Tracto Inferior. Preferentemente lavado broncoalveolar, esputo (si es posible) y/o aspirado endotraqueal. Se recogen en recipientes sin necesidad de medio de cultivo.

3. Otra limitación que se puede intentar solventar, es el hecho de que la TR-PCR no nos da información acerca de la vitalidad del virus en materiales inertes. Para saberlo, simplemente se realizan pruebas microbiológicas. Los profesionales de laboratorio optan por inocular una muestra objetivo a un cultivo de células. El virus o agente patógeno ataca y el microscopio evidencia los estragos.
Luego, con la TR-PCR se identifica si el culpable de ese estrago es el SARSCoV-2.

4. Detectar rápidamente el ARN vírico es la principal limitación de la TR-PCR, pero es debido a la cantidad de pruebas que se envían a los laboratorios y la cantidad de respuestas urgentes que se necesitan.

Se han desarrollado nuevas pruebas de detección rápida del ARN viral, como es el caso test para el diagnóstico rápido del Covid-19 desarrollado por el consorcio alemán Bosch, ahorra tiempo al hacer innecesario enviar las pruebas a un laboratorio para su análisis, permite en tan solo dos horas y media, verificar si existe o no una infección, en el mismo lugar en el que se toman las muestras, y tiene un 95\% de fiabilidad. Las muestras tomadas en garganta o fosas nasales de los pacientes, son introducidas en un cartucho con todos los reactivos necesarios para el análisis. Luego se introduce en un aparato de análisis, el cual puede ser manejado por personal no especializado.

Otras pruebas de detección rápidas son los test de anticuerpos, que son especialmente seleccionados, los cuales reconocen y se fijan con una alta especificidad, a proteínas situadas en la superficie del virus. En ciertas condiciones, la especificidad de esa unión se compara a las cadenas genéticas de la PCR. Este test revela en minutos (15 minutos) si el virus está presente, a través de una reacción colorimétrica. El desarrollo de tales pruebas no es un proceso sencillo, en comparación con RT-PCR que encajan con exactitud, y los anticuerpos son moléculas complejas que no se pueden encargar fácilmente. Sin embargo, muchos expertos confían en este tipo de prueba rápida, que podría estar disponible en el plazo de semanas o meses.

Complementar o sustituir la RT-PCR con estas pruebas rápidas de detección de este nuevo coronavirus dependerá de muchos 
factores, entre el más importante está el económico: los recursos con los que cuenta cada sistema de salud de cada país del mundo. La disponibilidad de estas pruebas no son fáciles de conseguir, y la aplicación de las mismas en cantidades extraordinaria requiere de gran esfuerzo y trabajo por parte de los profesionales de la salud, laboratorios y demás instituciones.

Existen muchas pruebas que consisten básicamente en detectar si la persona está o no contagiada, y en detectar si alguien estuvo o no expuesto al virus. Conjuntamente con la propagación de la pandemia, van surgiendo nuevos métodos y enfoques analíticos de la mano de los investigadores. Desde las pruebas clásicas como la PCR, hasta las complejas nanotecnologías ópticas, se exponen y se ofrecen al mundo. Pero obviamente, aunque existe una disposición global para garantizar la distribución justa de todas las tecnologías sanitarias esenciales para hacer frente a la pandemia de COVID-19, la realidad es que no todos los lugares del mundo puedan contar con la asistencia de calidad y control oportuno de la pandemia.

Es por ello, que lo clásico y seguro se oferta al mundo y se sugieren pruebas como la PCR con la Transcriptasa Inversa para diagnosticar el COVID-19, y para, además, conseguir hallazgos que ofrezcan más información sobre el comportamiento de esta pandemia. Para ello la OMS sugiere estandarizar en todos los países del mundo, los reactivos y métodos, para que todos los resultados puedan ser comparables, para posteriores estudios.

\section{Conclusiones}

Existen dos tipos de pruebas principales que utilizan los países en medio de la pandemia del COVID-19: Las pruebas serológicas que pueden ofrecer resultados rápidos sobre si la persona estuvo expuesta al virus, y las pruebas moleculares que tardan unas dos o tres horas, que evidencian si la persona está infectada o no con SARS-CoV-2. Sobre estas últimas pruebas, la técnica de elección ha sido la RT-PCR, por ser la más confiable, y porque es la más conocida en todo el mundo. La Organización Mundial de Salud, la ha sugerido como prueba principal, para que todos los resultados sean los más exactos posibles y comparables entre laboratorios. La OMS ha hecho público los reactivos a utilizar y el método para realizar la determinación de Covid-19. Además, la RT-PCR ha sido la más confiable para determinar si un paciente tiene la enfermedad, y la gravedad de la misma con la fluorescencia que se realiza en cada ciclo PCR que se muestra, en tiempo real, por pantalla.

Se puede decir que el inconveniente y limitación más importante que presenta la TR-PCR, es el tiempo que tarda en reportar los resultados, que dada la emergencia y demanda de la pandemia, ha resultado un poco ineficiente para reportar oportunamente la información. Sin embargo, cada país se las ha arreglado para manejar la situación usando otras pruebas diagnósticas que complemente la PCR.

En definitiva, ninguna prueba es 100\% infalible, muchos estudios en medio de la pandemia, así lo han demostrado. Por tanto, el diagnóstico del COVID-19 no debe realizarse únicamente en función del resultado de las pruebas, sino teniendo en cuenta, principalmente, la clínica del paciente. Tal vez sea necesario repetir las pruebas según criterio médico, porque un resultado negativo no significa necesariamente que la infección no esté presente.

\section{Bibliografía}

Roche. (23 de 05 de 2020). Obtenido de https:// diagnostics.roche.com/es/es/article-listing/historyof-pcr.html

AsianScientist . (23 de 05 de 2020). COVID-19 Diagnostics Explained. Obtenido de https:// www.asianscientist.com/2020/04/features/covid-19-diagnostics-explained/ 
BBC News Mundo. (25 de 04 de 2020). Tests de coronavirus: cómo son las pruebas serológicas y moleculares para detectar el covid-19 y qué ventajas e inconvenientes tienen. Recuperado el 23 de 05 de 2020, de https://www.bbc.com/mundo/ noticias-52361548

Biocompare. (25 de 05 de 2020). RT-PCR (Reverse Transcriptase PCR). Obtenido de https://www.biocompare.com/PCR-Real-Time-PCR/6896-RT-PCR/

Dorado Pérez, G. (23 de 05 de 2020). UCO. Obtenido de 44. Amplificación de DNA mediante PCR (Reacción en Cadena de la Polimerasa): http:// www.uco.es/organiza/departamentos/bioquimica-biol-mol/pdfs/44\%20PCR.pdf

Investigación y Ciencia. (03 de 04 de 2020). COVID-19: ¿Cómo funcionan las nuevas pruebas del coronavirus? Obtenido de https://www.investigacionyciencia.es/noticias/covid-19-cmo-funcionan-las-nuevas-pruebas-del-coronavirus-18503

OMS. (16 de 03 de 2020). Alocución de apertura del Director General de la OMS en la rueda de prensa sobre la COVID-19 celebrada el 16 de marzo de 2020. Recuperado el 24 de 05 de 2020, de https:// www.who.int/es/dg/speeches/detail/who-directorgeneral-s-opening-remarks-at-the-media-briefingon-covid-19---16-march-2020
OMS. (20 de 05 de 2020). WHO Director-General's opening remarks at the media briefing on $\mathrm{CO}$ VID-19 . Obtenido de https://www.who.int/dg/ speeches/detail/who-director-general-s-openingremarks-at-the-media-briefing-on-covid-19---20may-2020

ORGANIZACIÓN MUNDIAL DE LA SALUD (OMS). (2016). Estrategia Mundial del Sector de la Salud Contra las Hepatitis Víricas 2016-2021. Hacia el fín de las hepatitis Víricas. WHO Document Production Services, Geneva, Switzerlan.

SiNC. (2008). Recuperado el 22 de 05 de 2020, de Kary Mullis, el nobel excéntrico que vino a España a comprar azulejos: https://www.agenciasinc.es/Reportajes/Kary-Mullis-el-nobel-excentrico-que-vino-a-Espana-a-comprar-azulejos

World Health Organization. (2020). Clinical management of severe acute respiratory infection (SARI) when COVID-19 disease is suspected. Global Expert Panel for their input: WHO.

Xie, C., Jiang, L., Huang, G., Pu, H., Gong, B., Lin, H., ... Long, B. (2019). Comparison of different samples for 2019 novel coronavirus detection by nucleic acid amplification tests. El Sevier, 93, 264267.

\section{CITAR ESTE ARTICULO:}

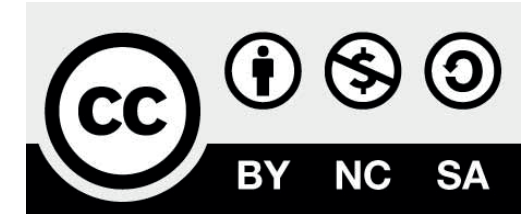

RECONOCIMIENTO-NOCOMERCIAL-COMPARTIRIGUAL CC BY-NC-SA

ESTA LICENCIA PERMITE A OTROS ENTREMEZCLAR, AJUSTAR Y CONSTRUIR A PARTIR DE SU OBRA CON FINES NO COMERCIALES, SIEMPRE Y CUANDO LE RECONOZCAN LA AUTORÍA Y SUS NUEVAS CREACIONES ESTÉN BAJO UNA LICENCIA CON LOS MISMOS TÉRMINOS.

Salazar Carranza, L., Maldonado Santacruz, F., \& Cruz Villegas, J. (2020). La PCR como prueba para confirmar casos vigentes de COVID-19. RECIMUNDO, 4(2), 60-70. doi:10.26820/recimundo/4.(2).mayo.2020.64-74 